\title{
Fasting and Two-hour Post-Load Glucose Levels for the Diagnosis of Diabetes
}

\author{
The Relationship between Glucose Levels and Complications of Diabetes in the Pima Indians
}

\author{
N. B. Rushforth ${ }^{1}$, M. Miller $\dagger^{2}$, and P. H. Bennett ${ }^{3}$ \\ 1,2Departments of Biology and Biometry, and Medicine, Case Western Reserve University, Cleveland, Ohio, and \\ ${ }^{3}$ Southwestern Field Studies Section, Epidemiology and Field Studies Branch, National Institute of Arthritis, Metabolism, \\ and Digestive Diseases, Phoenix, Arizona, USA
}

\begin{abstract}
Summary. The frequency distributions of both the fasting and two-hour post-load plasma glucose levels were bimodal in the Pima Indian population aged 25 years and over. The hyperglycaemic component of this distribution represents those with diabetes mellitus, as some 30 percent of this group had evidence of the specific vascular complications of the disease, whereas these abnormalities were virtually absent in those with lower glucose levels. The bimodal characteristics of the frequency distributions were utilized to define optimal criteria to separate those with and without diabetes. The sensitivity and specificity of these criteria for fasting and two-hour glucose levels were compared and were found to be similar. The fasting glucose determination, however, was more reproducible and stable, as well as being easier to obtain, indicating that it is the better measurement for diagnostic purposes. The optimal level for diagnosis of $7.5 \mathrm{mmol} / 1(136 \mathrm{mg} / \mathrm{dl})$ for the fasting glucose and the equivalent two-hour value of $14 \mathrm{mmol} / \mathrm{l}$ $(250 \mathrm{mg} / \mathrm{dl})$, were higher than many previously recommended diagnostic levels. Nevertheless, there was no evidence that subjects with lower levels were at appreciable risk of developing the specific complications of diabetes. Subjects with impaired glucose tolerance (IGT), but without fasting hyperglycaemia, should not be diagnosed as having diabetes mellitus.
\end{abstract}

Key words: Two-hour plasma glucose, fasting plasma glucose, bimodality, oral glucose tolerance tests, Pima Indians, diagnosis, diabetes, sensitivity, specificity, misclassification, retinopahy, nephropathy.

The diagnosis of diabetes mellitus was based originally on the classical symptoms of polyphagia, polydipsia, and polyuria and the presence of reducing substance (sugar) in the urine. When blood glucose measurements became available, the presence of a high fasting blood glucose concentration was accepted as the best criterion for diagnosis. Subsequently, the glucose tolerance test was introduced as a more sensitive test useful for the identification of diabetes which had not yet advanced to the stage of fasting hyperglycaemia or overt diabetes [1].

When deciding upon criteria for diagnosis, the mean value plus two standard deviations of the blood glucose concentrations in subjects without known diabetes or a family history of diabetes were used to define the upper limits of normality $[2,3]$. These criteria were arbitrary and had undefined properties since the frequency distributions of both fasting and post-load glucose levels in most populations were subsequently found to be unimodal and skewed [46].

The glucose tolerance test interpreted according to such criteria led to the identification of many subjects with abnormally high one-hour and/or twohour post-load levels, but with normal fasting values, who were generally presumed to be diabetic. The validity of the diagnosis of diabetes based on the presence of only impaired glucose tolerance (IGT), however, has been recently questioned $[7,8]$.

The majority of subjects with IGT do not show unequivocal evidence of diabetes mellitus, within five years or even 8-10 years later [9-12], although they do have an increased risk of decompensation to clinical diabetes [13] and are perhaps more prone to atherosclerosis e.g. coronary heart disease, than those with unequivocally normal post-load glucose levels $[14,15]$. Nevertheless, if diabetes mellitus is defined as a syndrome characterized by disordered carbohydrate metabolism and associated with the occurrence of specific vascular complications, such as retinopathy and nephropathy, persons with IGT only should not receive the diagnosis of diabetes unless it 
Table 1. Number of Pima subjects by age, sex, and diabetes treatment status

\begin{tabular}{|c|c|c|c|}
\hline \multirow[b]{2}{*}{$\begin{array}{l}\text { Age in } \\
\text { years }\end{array}$} & \multicolumn{3}{|c|}{ Number of subjects } \\
\hline & Total & $\begin{array}{l}\text { Recently } \\
\text { treated }^{\mathrm{a}}\end{array}$ & $\begin{array}{l}\text { Not recently } \\
\text { treated }\end{array}$ \\
\hline \multicolumn{4}{|l|}{ Males } \\
\hline $5-14$ & 144 & 0 & 144 \\
\hline $15-24$ & 140 & 1 & 139 \\
\hline $25-34$ & 72 & 7 & 65 \\
\hline $35-44$ & 74 & 14 & 60 \\
\hline $45-54$ & 56 & 15 & 41 \\
\hline $55+$ & 66 & 16 & 50 \\
\hline Total males & 552 & 53 & 499 \\
\hline \multicolumn{4}{|l|}{ Females } \\
\hline $5-14$ & 166 & 0 & 166 \\
\hline $15-24$ & 228 & 3 & 225 \\
\hline $25-34$ & 127 & 7 & 120 \\
\hline $35-44$ & 114 & 32 & 82 \\
\hline $45-54$ & 85 & 29 & 56 \\
\hline $55+$ & 94 & 28 & 66 \\
\hline Total females & $\overline{814}$ & 99 & 715 \\
\hline $\begin{array}{l}\text { Total } \\
\text { males and females }\end{array}$ & 1366 & 152 & 1214 \\
\hline
\end{tabular}

a Subjects who had taken insulin (regular or NPH), tolbutamide acetohexamide or phenformin on day of or day prior to the test, or chloropropamide within two days before the day of the test

can be demonstrated that they too have an appreciable risk of developing these specific complications [8]. Reasons for distinguishing subjects with diabetes from those who have only IGT include patient management considerations, the prognostic, economic and psychological disadvantages of the diagnosis of diabetes, as well as the importance of identifying as precisely as possible those at risk of developing the complications of diabetes so that their aetiology and pathogenesis may be investigated, and the effects of treatment, aimed at preventing their development assessed.

Previous studies in the Pima Indians have shown that the population has a very high prevalence of diabetes and that the distributions of the two-hour post-load glucose levels in the adult population are bimodal $[16,17]$. This characteristic allows the population to be separated into a hyperglycaemic group, which has a high prevalence of retinopathy [18] and nephropathy [19] - suggesting that this group does constitute those with diabetes mellitus [20], and a second group with lower glucose levels who do not have these complications. While the latter may be at risk of developing diabetes in the future, they do not have it at this time.
We now report the presence of bimodality in fasting glucose levels as well as in the two-hour post-load glucose levels, which has enabled us to define the limits of fasting hyperglycaemia and permitted comparison of the usefulness of the fasting and post-load glucose levels for the diagnosis of diabetes. We have also examined the relationship of these glucose levels to the frequency of retinal and renal complications.

\section{Patients and Methods}

Glucose tolerance tests were performed on 552 male and 814 female Pima Indians aged 5-89 years residing on the Gila River Indian Reservation, 40 miles southeast of Phoenix, Arizona. Each participant, or parent/guardian, gave consent before examination. Each subject was tested in the morning, having fasted during the previous eight hours, and, if receiving diabetes treatment, omitting any hypoglycaemic medication prior to the test or that day. In 201 of the subjects glucose tolerance was retested up to $2^{1 / 2}$ years later. In 37 subjects retesting was performed up to 3 months later to determine reproducibility of the test and in 164 subjects the retesting took place between one and a half and two and a half years later to determine the long term stability of the measurements.

After a fasting venous blood sample was collected into a sodium fluoride-containing tube, an oral $75 \mathrm{~g}$ carbohydrate load (Dexcola, Custom Labs, Baltimore, MD) was given and a further venous blood sample was drawn two hours later. Blood samples were centrifuged and separated. Plasma glucose was measured using the Autoanalyzer ferricyanide method (Technicon Methodology File N-2).

Following mydriasis, ophthalmoscopic examinations were done without knowledge of the glucose levels or diabetic status of the subjects. The presence of "red dots" (microaneurysms or haemorrhages) or proliferative changes (new vessels, vitreous haemorrhage, fibrous strands and retinal detachment) were taken to represent retinopathy. A random urine specimen was obtained, and in all showing a trace or more of protein by dipstick, the protein concentration was measured using the Shevsky-Stafford method [21] and the urine creatinine concentration determined. The ratio of the protein/creatinine concentration, if $\geqslant 1$, in the absence of other well-defined non-diabetic causes of proteinuria, was considered to indicate nephropathy.

As hypoglycaemic treatment could influence the glucose levels all subjects currently receiving hypoglycaemic drugs were excluded (see Table 1) and the results from the remaining 1214 subjects were analysed.

Frequency distributions of the fasting and two-hour plasma glucose levels were plotted for each sex and in each decade and were bimodal above 25 years of age. The distributions were then examined using an iterative maximum likelihood procedure to determine the parameters of a model of two overlapping Gaussian distributions, which had been shown to describe satisfactorily the distributions of the logarithms of the two-hour glucose levels [17]. Chi square goodness of fit tests were used to compare the observed and predicted distributions. Cut-off points and probabilities of misclassification, were also estimated using the model [22].

As the two distributions of the model overlap, the use of a single cut-off point to divide the distribution will result in some misclassification of normals as diabetic, and vice versa. An optimum cut-off point, which corresponds to the intersection of the two overlapping distributions and which minimizes the degree of misclassification, can be determined algebraically using the parameters of the model (i. e. the means and standard deviations 

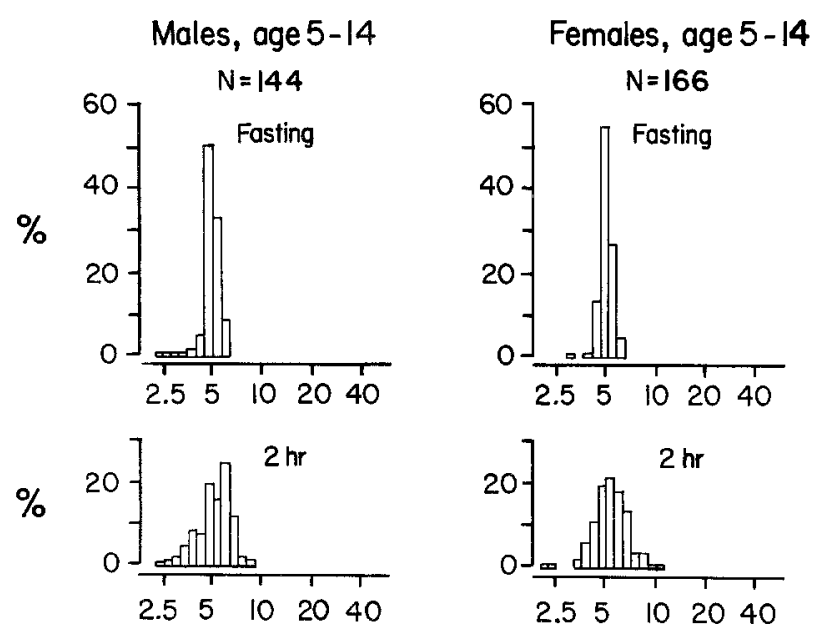

a
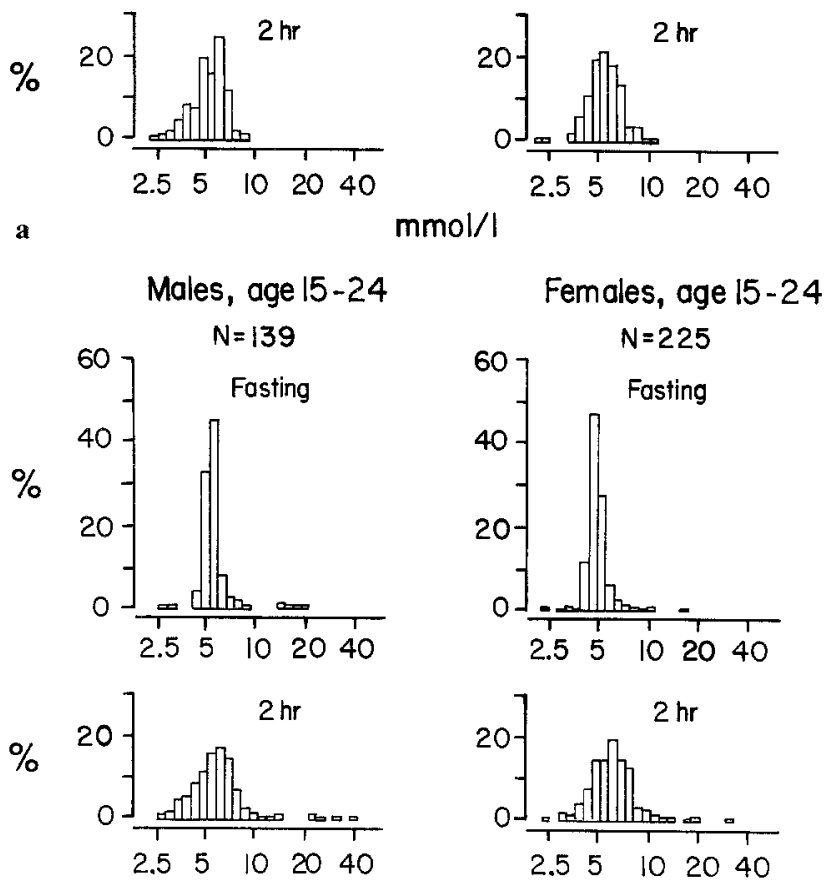

b
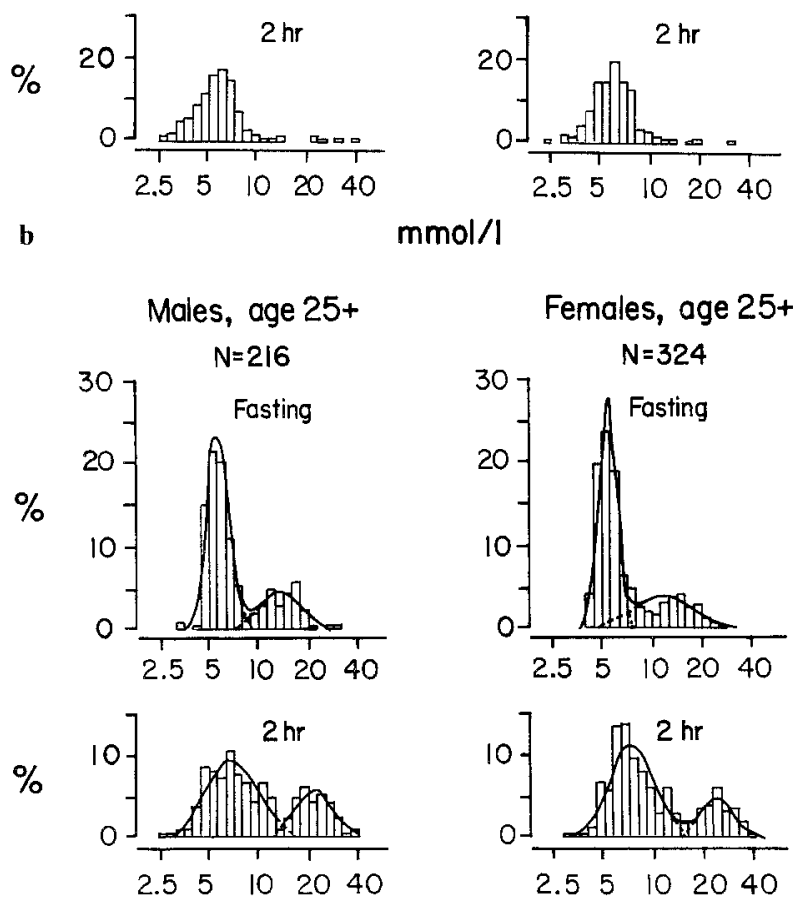

c

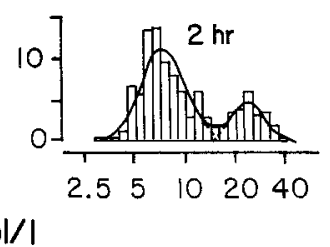

Fig. 1 a-c. Frequency distributions of fasting and two-hour postload venous plasma glucose levels (log. scale) in males and females aged a 5-14 years b 15-24 years and $\mathbf{c} 25$ years and over. The observed values are shown as histograms, upon which are superimposed the composite distribution of the model and its component curves of the components the proportion falling in each). The proportions of subjects misclassified were also estimated, although the specific individuals who are mislabelled cannot be identified.

\section{Results}

The age and sex distribution of the subjects included are shown in Table 1 . There were 152 subjects in the sample currently receiving hypoglycaemic drugs for the treatment of previously recognised diabetes, who were excluded. The distribution of the glucose values from the remainder were plotted. They comprised those not known to have diabetes at the time of the test or, if previously known, who had not recently received hypoglycaemic drugs and whose glucose levels were, therefore, unlikely to be influenced by previous medications. The distributions of the fasting and two-hour glucose levels of these subjects are shown in Figure $1 \mathrm{a}-\mathrm{c}$.

In the 5-14 year olds the distribution of both the fasting and two-hour glucose levels were unimodal (Figure 1a). In the 15-24 year olds (Figure 1b) there appeared outlying observations beyond the main distribution, and these appear to represent the only evidence of the hyperglycaemic members of the population in this age group.

The glucose values were bimodal for both fasting and two-hour levels in Pima males and females for each group above 25 years of age (Figure $1 \mathrm{c}$ ). The model of composite Gaussian distributions appeared to conform reasonably to the observed distributions, and goodness of fit tests performed in each sex and age group showed that the correspondence of the model was satisfactory in six of the eight fasting, and seven of the eight two-hour distributions.

Figure 2 shows the means of the normal and hyperglycaemic components of the distributions in those aged 25 years and over. The respective standard deviations and proportions falling in each of the components were also calculated. These are estimates derived from the two components of the model distributions which provide the best fit for the observed bimodal distributions of the glucose levels in each age-sex group. The means of the first component were consistently lower and rose less rapidly with age for the fasting glucose levels than those of the two-hour levels in both sexes. The standard deviations of the first component were consistently smaller for the fasting glucose levels than those of the two-hour levels. The means of the hyperglycaemic component were also consistently lower for the fasting than for the two hour glucose levels, but in neither sex did the mean fasting or two-hour level change significantly with age. 
Table 2. Percent ( \pm SEM) of hyperglycaemic subjects and percent of subjects misclassified on the basis of A) fasting and B) two-hour postload glucose values in those aged 25 years and over

Plasma glucose

\begin{tabular}{|c|c|c|c|c|c|c|c|c|c|}
\hline \multirow[b]{2}{*}{$\begin{array}{l}\text { Age in } \\
\text { years }\end{array}$} & \multirow[b]{2}{*}{$\begin{array}{l}\text { No. } \\
\text { examined }\end{array}$} & \multicolumn{4}{|l|}{ A) Fasting } & \multicolumn{4}{|c|}{ B) Two-hour } \\
\hline & & $\begin{array}{l}\text { With } \\
\text { hyper- } \\
\text { glycaemiaa } \\
\%\end{array}$ & $\begin{array}{l}\text { Sensitivity } \\
\%\end{array}$ & $\begin{array}{l}\text { Specificity }{ }^{\mathrm{d}} \\
\%\end{array}$ & $\begin{array}{l}\begin{array}{l}\text { Mis- } \\
\text { classified }^{b}\end{array} \\
\%\end{array}$ & $\begin{array}{l}\text { With } \\
\text { hyper- } \\
\text { glycaemia } \\
\%\end{array}$ & $\begin{array}{l}\text { Sensitivity } \\
\%\end{array}$ & $\begin{array}{l}\text { Specificity } \\
\%\end{array}$ & $\begin{array}{l}\begin{array}{l}\text { Mis- } \\
\text { classified }^{b}\end{array} \\
\%\end{array}$ \\
\hline \multicolumn{10}{|l|}{ Males } \\
\hline $25-34$ & 65 & $19.5(6.3)$ & 87.7 & 99.6 & 2.8 & $22.5(8.5)$ & 89.6 & 98.3 & 3.6 \\
\hline $35-44$ & 60 & $39.0(6.4)$ & 99.6 & 99.8 & 0.3 & $42.6(6.7)$ & 98.8 & 97.9 & 1.7 \\
\hline $45-54$ & 41 & $35.4(8.2)$ & 95.5 & 99.4 & 2.0 & $27.1(13.4)$ & 87.5 & 95.0 & 7.0 \\
\hline $55+$ & 50 & $21.3(6.9)$ & 90.5 & 99.0 & 2.8 & $28.3(8.0)$ & 97.1 & 98.6 & 1.8 \\
\hline \multicolumn{10}{|c|}{ Females } \\
\hline $25-34$ & 120 & $18.2(5.3)$ & 76.7 & 99.4 & 4.7 & $9.4(2.8)$ & 97.1 & 99.8 & 0.5 \\
\hline $35-44$ & 82 & $32.7(9.7)$ & 83.5 & 98.4 & 6.5 & $38.3(10.7)$ & 91.3 & 96.3 & 5.6 \\
\hline $45-54$ & 56 & $50.5(6.8)$ & 99.4 & 99.8 & 0.4 & $49.5(6.8)$ & 99.7 & 99.6 & 0.4 \\
\hline $55+$ & 66 & $42.3(7.6)$ & 89.2 & 98.6 & 5.4 & $28.0(6.7)$ & 96.0 & 96.8 & 3.4 \\
\hline
\end{tabular}

a Proportion estimated to lie in hyperglycaemic component of distribution

b Proportion of diabetics classified as non-diabetic, and vice versa, by application of a single cut-off value

c Sensitivity $=$ See text for definitions

d Specificity $=$ See text for definitions

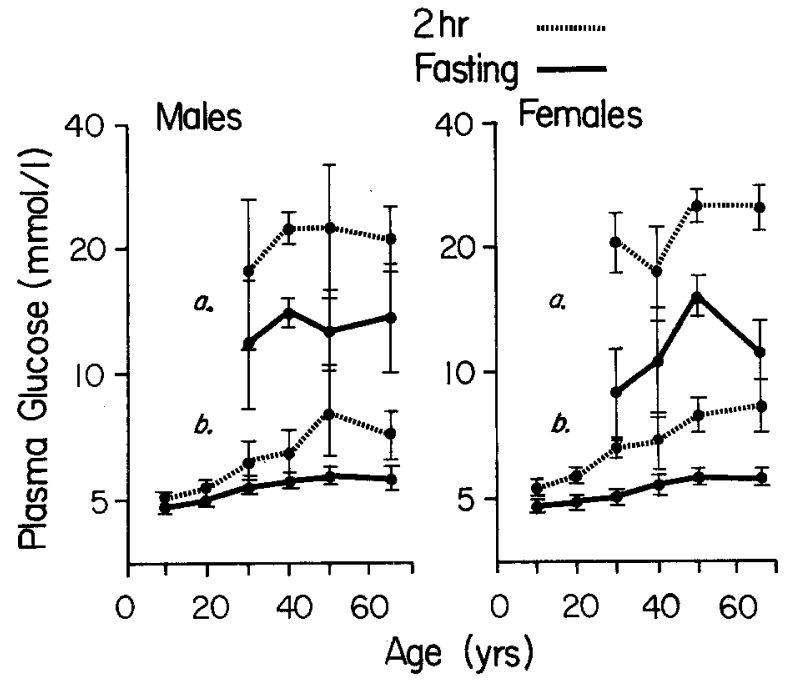

Fig. 2. Mean ( \pm SEM) of fasting and two-hour post-load glucose levels (log. scale) of the a hyperglycaemic, and $\mathbf{b}$ normal components of the bimodal frequency distributions by age for males $(\mathrm{n}=$ 499) and females $(\mathrm{n}=715)$

Table 3. Test-retest measurements of plasma glucose values for fasting and two-hour post glucose load. Mean ( \pm SEM) of absolute difference between two plasma glucose determinations $(\mathrm{mmol} / \mathrm{l})$

\begin{tabular}{lll}
\hline & \multicolumn{2}{l}{ Retest interval } \\
\cline { 2 - 3 } & Up to 3 months & 1.5 to 2.5 years \\
\hline $\mathrm{n}$ & 37 & 164 \\
Fasting & $1.6 \pm 0.3$ & $2.2 \pm 0.2$ \\
Two hour & $2.4 \pm 0.3$ & $4.1 \pm 0.4$ \\
P value & $<0.01$ & $<0.01$ \\
\hline
\end{tabular}

Table 2 shows the proportion of subjects aged 25 years and over who fell into the hyperglycaemic component of the fasting and the two-hour glucose distributions. In each corresponding age and sex group the proportions identified as hyperglycaemic by either the fasting or the two-hour levels did not differ significantly although, as might be expected, the proportions tended to increase with age, but then fell in the older age groups.

The optimal cut-off point to separate subjects who fell into each of the components of the frequency distributions was calculated using the means, standard deviations and proportions of subjects of each component of the distributions [22]. This cut-off point minimizes the probabilities of misclassifying individuals and, based on the model, the proportion of subjects misclassified can be estimated. The proportions correctly and incorrectly classified as hyperglycaemic, and vice versa, can be expressed in terms of sensitivity, that is the proportion correctly classified within the hyperglycaemic component; and specificity, the proportion of those who are correctly classified in the other component of the distributions. These values are also shown in Table 2. If the hyperglycaemic component of the glucose distributions does correspond to the diabetic population (vide infra), then use of the optimal cut-off point to separate the diabetics from the remainder results in a sensitivity ranging between 76.7 and 99.6 percent and a specificity ranging between 98.4 and 99.8 percent for the fasting glucose levels, and the corresponding point for the two-hour glucose levels gives 
Table 4. Retinopathy and/or nephropathy according to fasting and two-hour plasma glucose in subjects aged 25 and over [Number with complications (c); Number tested (n)]

\begin{tabular}{|c|c|c|c|c|c|c|c|c|c|c|c|c|c|c|c|c|c|c|c|c|c|c|}
\hline \multirow{3}{*}{\multicolumn{2}{|c|}{$\begin{array}{l}\text { Two-hour } \\
\text { glucose } \\
\text { (mmol/1) }\end{array}$}} & \multicolumn{21}{|c|}{ Fasting glucose $(\mathrm{mmol} / \mathrm{l})$} \\
\hline & & \multicolumn{2}{|c|}{$<5.0$} & \multicolumn{2}{|c|}{$5.0-$} & \multicolumn{2}{|c|}{$6.0-$} & \multicolumn{2}{|c|}{$7.0-$} & \multicolumn{2}{|c|}{$8.0-$} & \multicolumn{2}{|c|}{$9.0-$} & $11.0-$ & \multicolumn{2}{|c|}{$14.0-$} & \multicolumn{2}{|c|}{$18.0-$} & $22.0+$ & \multicolumn{2}{|c|}{ Total } & \multirow[t]{2}{*}{$\begin{array}{l}\% \text { with } \\
\text { complications }\end{array}$} \\
\hline & & $\bar{c}$ & $n$ & $\bar{c}$ & $\mathrm{n}$ & $\mathrm{c}$ & $\bar{n}$ & $\bar{c}$ & $\bar{n}$ & $\overline{\mathrm{c}}$ & $\bar{n}$ & & $\mathrm{n}$ & $\overline{\mathrm{c} n}$ & $\overline{\mathrm{c}}$ & $\mathrm{n}$ & $\overline{\mathrm{c}}$ & $\bar{n}$ & $\overline{\mathrm{c}} \mathrm{n}$ & $\overline{\mathrm{e}}$ & $\mathrm{n}$ & \\
\hline \multirow{2}{*}{$<5.0$} & c & $1^{\mathrm{a}}$ & & 0 & & 0 & & & & & & & & & & & & & & 1 & & \\
\hline & $\mathrm{n}$ & & 32 & & 20 & & 4 & & & & & & & & & & & & & & 56 & \\
\hline \multirow{2}{*}{$5.0-$} & $\mathrm{c}$ & 0 & & 0 & & 0 & & & & & & & & & & & & & & 0 & & \\
\hline & $\mathrm{n}$ & & 30 & & 34 & & 4 & & & & & & & & & & & & & & 68 & \\
\hline \multirow{2}{*}{$6.0-$} & $\mathrm{c}$ & 0 & & 0 & & 0 & & 0 & & & & & & & & & & & & 0 & & \\
\hline & $\mathrm{n}$ & & 19 & & 52 & & 7 & & 1 & & & & & & & & & & & & 79 & \\
\hline \multirow{2}{*}{$7.0-$} & c & 0 & & 0 & & 0 & & 0 & & & & & & & & & & & & 0 & & \\
\hline & $\mathrm{n}$ & & 15 & & 36 & & 4 & & 1 & & & & & & & & & & & & 56 & 0.3 \\
\hline $8.0-$ & c & 0 & & 0 & 21 & 0 & 10 & & & & & & & & & & & & & 0 & 35 & \\
\hline \multirow{2}{*}{$9.0-$} & c & 0 & 4 & 0 & $\alpha$ & 0 & & 0 & & & & & & & & & & & & 0 & 53 & \\
\hline & $\mathrm{n}$ & & 4 & & 23 & & 16 & & 3 & & & & & & & & & & & & 46 & I \\
\hline \multirow{2}{*}{$11.0-$} & c & 0 & & 0 & & 0 & & 0 & & $1^{\mathrm{b}}$ & & & & 0 & 0 & & & & & 1 & & \\
\hline & n & & 2 & & 10 & & 11 & & 13 & & 1 & & & 2 & & 1 & & & & & 40 & 2.5 \\
\hline \multirow{4}{*}{$\begin{array}{c}14.0- \\
18.0-\end{array}$} & c & & & 0 & & 0 & & $1^{\mathrm{c}}$ & & 1. & & 1 & & 2 & & & & & & 5 & & \\
\hline & $\mathrm{n}$ & & & & - 1 & & 4 & & 6 & & 4 & & 9 & 4 & & & & & & & 28 & 17.9 \\
\hline & c & & & & & 0 & & 0 & & 2 & & 1 & & 4 & 1 & & & & & 8 & & \\
\hline & $\mathrm{n}$ & & & & & & 2 & & 2 & & 4 & & 9 & 13 & & 9 & & & & & 39 & 20.5 \\
\hline \multirow{2}{*}{$22.0+$} & c & & & & & & & & & 1 & & 1 & & 10 & 9 & & 7 & & 2 & 30 & & : \\
\hline & $\mathrm{n}$ & & & & & & & & & & 2 & & 1 & 17 & & 37 & & 13 & 4 & & 74 & 40.5 \\
\hline \multirow{2}{*}{ Total } & c & 1 & & 0 & & 0 & & 1 & & 5 & & 3 & & 16 & 10 & & 7 & & 2 & 45 & & \\
\hline & $\mathrm{n}$ & & 106 & & 197 & & 62 & & 26 & & 11 & & 19 & 36 & & 47 & & 13 & 4 & & 521 & \\
\hline \multicolumn{2}{|c|}{$\begin{array}{l}\text { Percent with } \\
\text { complications }\end{array}$} & & & 0.3 & & & & 3.8 & & 45.4 & & 15. & & 44.4 & 21.3 & & 53.8 & & 50.0 & & & \\
\hline
\end{tabular}

a \#1365 Received 5 glucose tolerance tests between 1965 and 1976. Two-hour glucose levels ranged between 3.9 and 5.6 mmol/l $(70-101 \mathrm{mg} / \mathrm{dl})$ and had fasting levels of 4.7 and $4.9 \mathrm{mmol} / 1$ ( 84 and $89 \mathrm{mg} / \mathrm{dl})$. Had multiple injuries and head trauma. "Haemorrhage" or "exudates" recorded on 3 examinations

b $\# 199$ Diabetes for at least 10 years. Fasting plasma glucose $8.5 \mathrm{mmol} / \mathrm{l}(153 \mathrm{mg} / \mathrm{dl})$, two-hour plasma glucose $13.7 \mathrm{mmol} / \mathrm{l}(246 \mathrm{mg} / \mathrm{dl}) \mathrm{at}$ this time, had had previous fasting glucose level of $13.3 \mathrm{mmol} / 1(239 \mathrm{mg} / \mathrm{dl})$ and two-hour glucose levels of 16.8 to $25.4 \mathrm{mmol} / 1$ $(302-458 \mathrm{mg} / \mathrm{dl})$. Diabetic retinopathy for 7 years. Had lost $12 \mathrm{~kg}$ in weight prior to present test

c \#1038 Diabetes for 7 years. Has microaneurysms and exudates of recent onset. Fasting plasma glucose $7.4 \mathrm{mmol} / \mathrm{l}$ (133 mg/dl); two-hour level $15.4 \mathrm{mmol} / \mathrm{l}(278 \mathrm{mg} / \mathrm{dl})$. Previous two-hour glucose levels 17.4 to $25.2 \mathrm{mmol} / \mathrm{l}(314-454 \mathrm{mg} / \mathrm{dl})$ and previous fasting level of $10.5 \mathrm{mmol} / 1(189 \mathrm{mg} / \mathrm{dl})$. Had lost $16 \mathrm{~kg}$ in weight prior to present test

ranges of sensitivity of 87.5 to $99.7 \%$ and specificity of 95.0 to 99.8 percent. The total number of subjects misclassified, diabetics as normals, and normals as diabetics, using these cut-off points ranged between 0.3 and 6.5 percent for the fasting levels, and 0.4 to 7.0 percent for the two-hour levels.

The optimal cut-off points for the fasting and two-hour levels did not vary significantly between the sexes, nor significantly among the age groups, although the two-hour values tended to be more variable than those of the fasting level. The optimum level averaged $7.5 \mathrm{mmol} / \mathrm{l}(136 \mathrm{mg} / \mathrm{dl})$ for the fasting venous plasma glucose concentration and 13.9 $\mathrm{mmol} / \mathrm{l}(251 \mathrm{mg} / \mathrm{dl})$ for the two-hour value.

The reproducibility and stability of a test, in addition to the sensitivity and specificity, are important considerations in judging its precision and utility. The reproducibility of the fasting and two-hour glucose levels were assessed over a three month period and between $1 \frac{1}{1 / 2}$ and $2^{1 / 2}$ years after the initial test as shown in Table 3. The mean differences in the glucose levels in both the short-term and more prolonged intervals were over 50 percent greater, and the relative differences more than 30 percent greater, for the two-hour determinations than for the fasting values. Hence the fasting glucose levels tended to be more stable and reproducible than the two-hour levels.

If the cut-off points, as defined above, can be used to diagnose diabetes depends upon an independent determination of the question of whether the hyperglycaemic component contains individuals who do indeed have diabetes at the time of the test and whether those in the lower component do not. 'To assess this question the prevalence of retinal and renal complications were determined in relation to 
both the fasting and two-hour glucose determination, as shown in Table 4. This assessment was restricted to those aged 25 years and over because of the low frequency of subjects with hyperglycaemia and even lower frequency with complications below this age. Adequate examinations were available in 521 of the 540 subjects in this age group.

The specific complications were found almost exclusively in subjects with either fasting plasma glucose levels $\geqslant 8 \mathrm{mmol} / 1(144 \mathrm{mg} / \mathrm{dl})$ or two-hour glucose levels of $\geqslant 14 \mathrm{mmol} / 1(252 \mathrm{mg} / \mathrm{dl})$. These values correspond well to the glucose levels which separated optimally the two modes of the respective glucose distributions.

\section{Discussion}

The frequency distributions of fasting plasma glucose concentrations in the Pima Indians aged 25 years and over demonstrate unequivocal evidence of bimodality. Since bimodality has also been found in two-hour and one-hour glucose distributions in the Pima Indian population $[17,23]$, the demonstration of bimodality in fasting glucose emphasizes further that when the prevalence of diabetes is high, the hyperglycaemic component of the population can be identified as a discrete group, rather than as the tail of a skewed unimodal distribution. A high prevalence of both retinopathy and nephropathy, the most specific and pathognomonic complications of diabetes, was found only in subjects who were members the hyperglycaemic group. This demonstrates the clinical significance of such hyperglycaemia as a true indicator of diabetes mellitus.

Since a high proportion of subjects in the hyperglycaemic mode fulfill the ultimate requirement for diagnosis by already having these complications, the hyperglycaemic group can be considered to have diabetes according to the previously stated definition. In contrast, specific complications were virtually absent in subjects in the lower component, and, while some may develop higher glucose levels in the future, there is no evidence that they carry an appreciable risk of developing specific complications as long as their glucose levels remain below the dividing value. Thus, the lower component of the glucose distribution contains subjects who were not diabetic at the time of the test.

The present study provides evidence that the fasting glucose level is at least as good as the two-hour glucose value as indicating diabetes. While the twohour glucose level is a risk factor for the eventual development of diabetes [13] the usefulness of fasting glucose levels to predict the subsequent develop- ment of the disease has not yet been evaluated. The fasting glucose level has a similar degree of sensitivity and specificity as the two-hour level for diagnostic purposes. Using the optimal criteria for separating the non-diabetic and diabetic subjects, the fasting and two-hour levels did not differ significantly in their ability to discriminate the groups who had or had not developed the specific complications of diabetes mellitus. Nevertheless, the short term and long term reproducibility and stability of the fasting determination were greater than for the two-hour levels.

The cut-off points derived from this study may be compared with those derived elsewhere for the diagnosis of diabetes and are considerably higher than have often been suggested by other workers [e.g. 3, 23].

The diagnostic levels suggested by this analysis of the Pima Indian data could be peculiar to the American Indian. Bimodality of fasting and two-hour postload glucose levels, has also been found in two other unrelated populations with a high prevalence of diabetes, the Nauruans, a Micronesian population [25], and the Samoans - a Polynesian group (P. Zimmet, personal communication). In both, the antimode between the two components of the glucose distributions is at a level quite similar to that found in the Pima Indians [26]. This suggests that the observations in the Pima may have much wider applicability than to the American Indian population alone.

Most sets of criteria for the diagnosis of diabetes have been derived, not by determining the lower boundaries of the range of glucose levels among subjects with unequivocal and/or independent evidence of diabetes, but rather by estimating the upper boundary of glucose levels in subjects who were believed not to have diabetes. This approach can be faulted in several ways. Firstly, this strategy assumes that impairment of glucose tolerance and diabetes are synonymous. There are, however, many conditions associated with IGT, such as obesity, atherosclerosis, cirrhosis, malnutrition, etc., which may, or may not be related to diabetes mellitus. Secondly, and most importantly, while individuals with impaired glucose tolerance may have an increased risk of developing fasting hyperglycaemia, there is little evidence that, as a group, they carry an appreciable risk of developing the specific complications which are regarded as pathognomonic of diabetes mellitus as long as they do not develop fasting hyperglycaemia. Jarrett and Keen [7], for example, reported the development and progression of retinopathy over a five year period only in persons with two-hour post $50 \mathrm{~g}$ glucose capillary blood sugars of $11.1 \mathrm{mmol} / 1(200 \mathrm{mg} / \mathrm{dl})$ and over and did not observe the development of significant 
retinopathy in the 248 subjects with baseline glucose levels of $6.7-11.1 \mathrm{mmol} / 1(120-199 \mathrm{mg} / \mathrm{dl})$. Neither have they seen it develop over a 6-8 year period in 204 male civil servants with similar glucose levels. The correspondence between these findings, and those derived among the Pima Indians, again suggests that the optimal criteria for the diagnosis of diabetes may be similar in most, if not all, populations.

The present study suggests that the glucose levels most commonly applied for the diagnosis of diabetes are too low and should be revised. When diagnostic glucose levels are defined for diabetes in the Pima Indians on the basis of either the points of optimum separation of the two components of the glucose distributions or on the basis of the levels at which the specific vascular complications of diabetes are found, the fasting or two-hour post-load levels have a similar ability to discriminate between those with and without diabetes. The fasting glucose level, however, is a more reproducible and stable measurement, and given the greater ease of measurement, appears to be the more desirable and reliable value upon which to base the diagnosis of diabetes mellitus.

Acknowledgements. We express our sincere thanks to the members of the Gila River Indian Community who participated in this study, to Mr. Otto Morgenstern and Ms. Wilma MacKay for computer programming, Ms. Mary Barham and Linda Phillips for technical services, and Ms. Janet Clark for secretarial assistance. This work was supported in part by NIH Contract NO1-AM-6-2221.

\section{References}

1. John, H. J.: Glucose tolerance and its value in diagnosis. J, Metab. Res. 1, 497-548 (1922)

2. Mayer, J. H., Womack, C. R.: Glucose tolerance 1. A comparison of four types of diagnostic tests in 103 control subjects and 26 patients with diabetes. Am. J. Med. Sci. 219, 161-173 (1950)

3. Fajans, S. S., Conn, J. W.: The early recognition of diabetes mellitus. Ann. N.Y. Acad. Sci. 82, 208-218 (1959)

4. Sharp, C. L., Butterfield, W. J. H., Keen, H.: Diabetes survey in Bedford 1962. Proc. R. Soc. Med. 57, 193-202 (1964)

5. U.S. Public Health Service: Glucose tolerance in aduits, United States 1960-62. Publication 1000, Series II, No. 2. Washington: U.S. Government Printing Office 1964

6. Hayner, N. S., Kjelsberg, M. D., Epstein, F. H., Francis, T.: Carbohydrate tolerance and diabetes in a total community, Tecumseh, Michigan. Diabetes 14, 413-423 (1965)

7. Siperstein, M. D.: The glucose tolerance test: A pitfall in the diagnosis of diabetes mellitus. Adv. Intern. Med. 20, 297-323 (1975)

8. Jarrett, R. J., Keen, H.: Hyperglycaemia and diabetes mellitus. Lancet 1976 II, 1009-1012

9. O'Sullivan, J.B., Mahan, C.M.: Prospective study of 352 young patients with chemical diabetes. N. Engl. J. Med. 278, 1038-1041 (1968)

10. Birmingham Working Party. Five year follow-up report on the
Birmingham diabetes survey of 1962 . Br. Med. J. 1970 III 301-305

11. Walker, J. B.: Ten year follow-up of diabetes in an English community. In: Diabetes epidemiology in Europe. Gutshe, $\mathrm{H}$., Holler, H. D. (Ed.), pp. 2-7. Stuttgart: Georg Thieme 1975

12. Carlstrom, S., Lundquist, A., Lundquist, I., Norden, A., et al.: Borderline glucose tolerance not followed by overt diabetes. Acta Med. Scand. 189, 415 (1971)

13. Hamman, R. F., Bennett, P. H., Miller, M.: Incidence of diabetes among Pima Indians. Adv. Metab. Disord. 9, 49-63 (1978)

14. Keen, H., Rose, G., Pyke, D. A., Boyns, D., Chlouverakis, C., Mistry, S.: Blood-sugar and arterial disease. Lancet 1965 II, 505-508

15. Epstein, F. H., Ostrander, L. D., Johnson, B. C., Payne, M. W., Hayner, N. S., Kelly, J.B., Francis, T., Jr.: Epidemiological studies of cardiovascular disease in a total community-Tecumseh, Michigan. Ann. Intern. Med. 62, 1170-1187 (1965)

16. Bennett, P. H., Burch, T. A., Miller, M.: Diabetes mellitus in American (Pima) Indians. Lancet 1971 II, 125-128

17. Rushforth, N.B., Bennett, P.H., Steinberg, A. G., Burch, T. A., Miller, M.: Diabetes in the Pima Indians: Evidence of bimodality in glucose tolerance distributions. Diabetes 20, 756-765 (1971)

18. Dorf, A., Ballintine, E. J., Bennett, P. H., Miller, M.: Retinopathy in Pima Indians; Relationship to glucose level, duration of diabetes, age at diagnosis of diabetes, and age at examination in a population with a high prevalence of diabetes mellitus. Diabetes 25, 554-560 (1976)

19. Kamenetzky, S., Bennett, P.H., Dippe, S., Miller, M. LeCompte, P. M.: A clinical and histologic study of diabetic nephropathy in the Pima Indians. Diabetes 23, 61-68 (1974)

20. Bennett, P. H., Rushforth, N. B., Miller, M., LeCompte, P. M.: Epidemiologic studies in diabetes in the Pima Indians. Recent Prog. Horm. Res. 32, 333-376 (1976)

21. Shevky, N. C., Stafford, D. D.: A clinical method for the estimation of protein in urine and other body fluids. Arch. Intern. Med. 32, 222-225 (1923)

22. Steinberg, A. G., Rushforth, N.B., Bennett, P.H., Burch, T. A., Miller, M.: On the genetics of diabetes mellitus. In: The pathogenesis of diabetes mellitus, Cerasi, E., Luft, R. (Ed.), pp. 237-264, Nobel Symposium 13. New York: John Wiley and Sons 1970

23. Rushforth, N. B., Bennett, P. H., Steinberg, A. G., Miller, M.: Comparison of the value of the two- and one-hour glucose levels of the oral GTT in the diagnosis of diabetes in Pima Indians. Diabetes 24, 538-546 (1975)

24. Mosenthal, H. O., Barry, E.: Criteria for an interpretation of normal glucose tolerance tests. Ann. Intern. Med. 33, 1175-1194 (1950)

25. Zimmet, P., Taft, P., Guinea, A., Guthrie, W., Thoma, K.: The high prevalence of diabetes mellitus on a Central Pacific Island. Diabetologia 13, 111-115 (1977)

26. Zimmet, P., Whitehouse, S.: Bimodality of fasting and twohour glucose tolerance distributions in a micronesian population. Diabetes 27, 793-800 (1978)

Received: May 16, 1978,

and in revised form: February 5, 1979

Dr. P. H. Bennett

NIAMDD

1440 E. Indian School Road

Phoenix, Az, 85014

USA 